University of Wollongong

Research Online

Faculty of Science, Medicine and Health -

Papers: part A

Faculty of Science, Medicine and Health

$1-1-2015$

\title{
The relative predictive validity of oxytocin and cortisol as biomarkers of psychological and physical wellbeing
}

Theresa A. Larkin

University of Wollongong, tlarkin@uow.edu.au

Susan J. Thomas

University of Wollongong, sthomas@uow.edu.au

Follow this and additional works at: https://ro.uow.edu.au/smhpapers

Part of the Medicine and Health Sciences Commons, and the Social and Behavioral Sciences

\section{Commons}

\section{Recommended Citation}

Larkin, Theresa A. and Thomas, Susan J., "The relative predictive validity of oxytocin and cortisol as biomarkers of psychological and physical wellbeing" (2015). Faculty of Science, Medicine and Health Papers: part A. 3263.

https://ro.uow.edu.au/smhpapers/3263

Research Online is the open access institutional repository for the University of Wollongong. For further information contact the UOW Library: research-pubs@uow.edu.au 


\title{
The relative predictive validity of oxytocin and cortisol as biomarkers of psychological and physical wellbeing
}

\author{
Abstract \\ Abstracts of the 45th Annual Meeting of the International Society of Psychoneuroendocrinology Stress \\ and the Brain: From Fertility to Senility John Mclntyre Conference Centre, Edinburgh, 8th - 10th September \\ 2015 \\ Disciplines \\ Medicine and Health Sciences | Social and Behavioral Sciences \\ Publication Details \\ Larkin, T. \& Thomas, S. (2015). The relative predictive validity of oxytocin and cortisol as biomarkers of \\ psychological and physical wellbeing. Psychoneuroendocrinology, 61 66-66.
}


The relative predictive validity of oxytocin and cortisol as biomarkers of psychological and physical wellbeing

Theresa Larkin*, Susan Thomas

University of Wollongong, NSW, Australia

The roles of oxytocin and cortisol are increasingly being investigated in psychological health; however, few studies have simultaneously examined the relative strength and direction of relationships between oxytocin and cortisol and indices of psycho-logical and physiological health. Understanding the endogenous balance of oxytocin and cortisol and their individual links to physical and mental health may improve biopsychosocial mod-els and interventions. We hypothesised that cortisol would predict psychopathology, whereas oxytocin would predict social connect-edness, and that both would be related to quality of life. We quantified morning plasma cortisol and oxytocin concentrations (via ELISA), blood pressure, body mass index and heart rate in 60 healthy participants. Additionally, participants completed com-prehensive measures of psychopathology, cognitive distortions, quality of life, stress and social connectedness. Correlational and regression methods were employed to estimate the relationships between variables. Plasma oxytocin (mean $=277 \pm 23 \mathrm{pg} / \mathrm{mL}$ ) and cortisol (mean $=107 \pm 8 \mathrm{ng} / \mathrm{mL}$ ) both showed high inter-individual variability, although this was larger for oxytocin. Both oxytocin and cortisol were significantly correlated with several distinct psycho-metric measures and physical indices of health. Morning cortisol predicted stress levels and psychopathology, whereas oxytocin pre-dicted perceived social connectedness and was negatively related to depressive cognitive distortions. Cortisol appears to be a better biomarker for overall psychopathology, stress and physical health while the role of oxytocin in cognitive distortions warrants further investigation. This study is one of the first to report on comprehen-sive data that links oxytocin, cortisol, indices of physical health and self-reported psychological wellbeing, with relevance to biopsy-chosocial models of health and clinical practice 